\title{
Long-term trends in international migration: lessons from macroeconomic model ${ }^{1}$
}

\author{
Frédéric Docquier ${ }^{2}$
}

\begin{abstract}
In this paper I develop a stylized model of the world economy and use it to explain the long-run trends in international migration. The model very well fits the trends of the last 40 years which are mainly governed by the evolution of population disparities between industrialized and developing countries. Then I provide migration projections for the 21st century and show that future migration is also governed by socio-demographic changes. I predict a robust increase in immigration pressures from sub-Saharan Africa and MENA countries to European countries.
\end{abstract}

Keywords: international migration, projections, world economy, inequality.

JEL codes: F22, F24, J11, J61, O15.

\section{Introduction}

Between 1960 and 2010 the worldwide stock of international migrants increased from 92 to 211 million at the same pace as the world population. Hence the worldwide share of migrants fluctuated at around 3\%. This average share masks comparatively significant differences between regions. In high-income countries (HIC) the foreign-born population increased more rapidly than the total population boosting the average proportion of foreigners from 4.5 to $11.0 \%$ (+6.5 percentage points). A remarkable fact is that this change is totally explained by the inflow of immigrants from developing countries, whose share in the total population increased from 1.5 to $8.0 \%$ (once again, +6.5 percentage points). By comparison the share of North-North migrants has been fairly stable. In less developed countries (LDC), the total stock of emigrants increased at the same pace as the total population leading to small fluctuations of the emigration rate between 2.6 and 3.0\%. As part of this emigration process the share of emigrants to HIC in the population increased from 0.5 to $1.4 \%$.

\footnotetext{
${ }^{1}$ Article received 1 October 2017, accepted 22 January 2018.

${ }^{2}$ FNRS and IRES Université catholique de Louvain, B-1348 Louvain-la-Neuve, Belgique, frederic.docquier@uclouvain.be.
} 
Hence the average propensity to emigrate from LDC to HIC has increased by less than one percentage point over half a century. The underlying root causes of these trends are known (demographic imbalances, economic inequality, increased globalization, political instability, etc.). However in quantitative terms little is known about their relative importance and about the changing educational structure of past migration flows. Furthermore the very same root causes of migration are all projected to exert a strong influence in the coming decades and little is known about the predictability of future migration flows. How does the recent literature contribute to gaining an understanding of the long-run trends in international migration? What lessons can be drawn from macroeconomic models? What can be expected for the 21 st century? These are the questions addressed in this paper.

The rest of the paper is organized as follows: Section 1 deals with the problem of predictive power of macroeconomic models. Section 2 investigates the root drivers of past migration. Section 3 describes a set of migration forecasts for the 21 st century. The paper is closed with conclusions

\section{Predictive power of macroeconomic models}

The recent empirical literature has produced consensus specifications for modelling the interactions between migration decisions and economic variables. On the one hand migration literature has shown that the propensity to emigrate from a given origin country to a given destination differs across skill groups (college graduates are more mobile than the less educated), increases with the income gap between the origin and the destination and varies with migration policies and dyadic factors such as distance, colonial links or linguistic proximity. The empirical literature has provided solid micro-foundations for empirical gravity regressions, as well as consensus estimates for the key elasticities. On the other hand, the labour market and growth literatures have shown that a CES (constant elasticity of substitution) production framework explains well the disparities in macroeconomic performance between countries and the patterns of wage inequality between skill groups. In this framework a rise in human capital mechanically increases the average income because highly educated workers are more productive. Furthermore greater contributions of human capital to productivity can be obtained when considering technological spill-over effects (aggregate TFP externalities or skill-biased externalities). However the size of these externalities has generated a certain level of debate.

Advantage was taken of these findings to construct an abstract model of the world economy, which highlights the major mechanisms underlying migration decisions and wage inequality in the long term. To keep it as simple 
as possible the model only relies on a migration technology and a production technology. ${ }^{3}$

The migration technology determines the condition under which migration to a destination country $j$ is profitable for workers of type $s$ (with $s=h$ for college-educated workers, and $s=l$ for the less educated), born in country $i$. The consensus gravity specification can be written as:

$$
M_{i j, s, t} / M_{i i, s, t}=P_{i j, s, t}=P\left(W_{j, s, t} / W_{i, s, t}, V_{i j, s, t}\right) \text {, }
$$

where $\mathrm{M}_{\mathrm{i} j \mathrm{s,t}}$ is the stock of individuals of skill $s$ moving from $i$ to $j$ at time $t$ ( $\mathrm{M}_{\mathrm{i} i \mathrm{i}, \mathrm{t}}$ is the number of non-migrants), $\mathrm{P}_{\mathrm{ij}, \mathrm{s}, \mathrm{t}}$ is the equilibrium ratio of migrantto-stayer, which depends on the wage ratio $\left(\mathrm{W}_{\mathrm{j}, \mathrm{s}, \mathrm{t}} / \mathrm{W}_{\mathrm{i}, \mathrm{s}, \mathrm{t}}\right)$ and a set of dyadic residual factors $\left(\mathrm{V}_{\mathrm{i}, \mathrm{s}, \mathrm{t}}\right)$. The latter dyadic factors account for the root drivers of migration such as distance, language, colonial links, other economic and sociological factors and migration policies. ${ }^{4}$ Some of these measures are difficult to measure. Note that all determinants are skill-specific.

Accrual over potential destinations yields:

$$
\sum_{\mathrm{j}} \mathrm{M}_{\mathrm{i} \mathrm{j}, \mathrm{s}, \mathrm{t}}=\mathrm{M}_{\mathrm{i} i \mathrm{~s}, \mathrm{t}} \sum_{\mathrm{j}} \mathrm{P}_{\mathrm{i} j \mathrm{~s}, \mathrm{t}}=\mathrm{N}_{\mathrm{i}, \mathrm{s}, \mathrm{t}}
$$

where $\mathrm{N}_{\mathrm{i}, \mathrm{s}, \mathrm{d}}$ denotes the size of the native (i.e. the before-migration) population of country $i$ at time $t$.

Taking the world distribution of income and the structure of the world native population $\left(\mathrm{N}_{\mathrm{i}, \mathrm{s}, \mathrm{t}}\right.$ for all $i, s$ and $\left.t\right)$ as given, Eqs (1)-(2) characterize the equilibrium allocation of the world population. In addition when this allocation $\mathrm{M}_{\mathrm{i} j, \mathrm{~s}, \mathrm{t}}$ is known accrual over all origin countries determines the size and structure of the resident population of each country $j: \sum_{\mathrm{i}} \mathrm{M}_{\mathrm{i} j \mathrm{j}, \mathrm{t}}=\mathrm{L}_{\mathrm{j}, \mathrm{s}, \mathrm{t}}$ (where $L$ stands for labour force).

The migration technology can be calibrated to match the allocation of the world adult population observed in 2010, the year for which dyadic migration data are available by education level (Arslan et al. 2015). Using wage proxies and assuming an elasticity of $\mathrm{P}_{\mathrm{i}, \mathrm{j}, \mathrm{t}}$ to $\mathrm{W}_{\mathrm{j}, \mathrm{s,t}} / \mathrm{W}_{\mathrm{i}, \mathrm{s}, \mathrm{t}}$ equal to 0.7 (as in Bertoli and Fernandez-Huertas Moraga, 2013), the parameterization of the migration technology consists of identifying the residual factors $V_{i, j, s, t}$ that equalize $M_{i j, s, t}$ with the observed stocks in 2010 .

In all countries the production technology determines total production $\left(\mathrm{Y}_{\mathrm{j}, \mathrm{t}}\right)$ and wage rates $\left(\mathrm{W}_{\mathrm{j}, \mathrm{s}, \mathrm{t}}\right)$ as a function of the size and structure of the resident population. It can be written as:

\footnotetext{
${ }^{3}$ Technical details can be found in Dao, Docquier, Maurel, \& Schaus (2017).

${ }^{4}$ Typically the random utility maximization model implies $\mathrm{M}_{\mathrm{i}, \mathrm{j}, \mathrm{t}} / \mathrm{M}_{\mathrm{i}, \mathrm{s}, \mathrm{t}}=\left(\mathrm{W}_{\mathrm{j}, \mathrm{s}, \mathrm{t}} / \mathrm{W}_{\mathrm{i}, \mathrm{s}, \mathrm{t}}\right)^{\alpha} \mathrm{V}_{\mathrm{i}, \mathrm{s}, \mathrm{t},}$ where $\alpha$ denotes the elasticity of bilateral migration to wage disparities.
} 


$$
Y_{j, t}=A_{j, t} F\left(\theta_{j, l, t} L_{j, l, t} \theta_{j, h, t} L_{j, h, t}\right) ; W_{i, s, t}=A_{j, t} F / L_{j, s, t}
$$

where $\mathrm{F}($.) is a CES transformation function of the number of high-skilled and low-skilled workers $\left(\mathrm{L}_{\mathrm{j}, \mathrm{t}, \mathrm{t}}\right), \mathrm{A}_{\mathrm{j}, \mathrm{t}}$ denotes the total factor productivity (TFP), $\theta_{\mathrm{j}, \mathrm{l}, \mathrm{t}}$ and $\theta_{\mathrm{j}, \mathrm{h,t}}$ are relative productivity parameters capturing the skill bias in production (such that $\theta_{\mathrm{j}, \mathrm{l}, \mathrm{t}}+\theta_{\mathrm{j}, \mathrm{h}, \mathrm{t}}=1$ ).

The production technology can be calibrated to match the data on income per capita and wage inequality in the year 2010. In line with the labour market literature (e.g. Ottaviano \& Peri, 2012; Angrist, 1995), the elasticity of substitution (ES) between college-educated and less educated workers varies between 1.5 and 3 . When ES is fixed, $\theta_{j, s, t}$ can be calibrated to exactly match wage inequality data and $\mathrm{A}_{\mathrm{j}, \mathrm{t}}$ can be calibrated to exactly match GDP data. As for schooling externalities, there is no consensus on their size. There is a distinction made between a maximalist and a minimalist scenario. In the maximalist scenario it is assumed that the elasticities of $\mathrm{A}_{\mathrm{j}, \mathrm{t}}$ and of $\theta_{\mathrm{j}, \mathrm{h}, \mathrm{t}} / \theta_{\mathrm{j}, \mathrm{l}, \mathrm{t}}$ to the proportion of college graduates are equal to the estimated correlation between these variables, ignoring the potential reverse causation relationship between them. In the minimalist scenario it is assumed that these elasticities are equal to zero.

The combination of endogenous migration decisions and equilibrium wages jointly determines the world distribution of income and the allocation of the world population. The calibration is such that the model exactly matches the economic and socio-demographic characteristics of the world in the year 2010. To assess the predictive power of this abstract macroeconomic model a set of retrospective simulations (or backcasts) was first conducted and compared with historical data. There is no database documenting past migration stocks by education level and by age group. Nonetheless Ozden, Parsons, Schiff, \& Walmsley (2011) and the United Nations provide decadal data on bilateral migration stocks from 1960 to 2010 with no disaggregation between age and skill groups. Thus the model to retrospectively simulate bilateral migration stocks by education level was used with aggregation over skill groups, origin and/or destination countries and a comparison of the simulated levels with observed migration stocks for the years 1970, 1980, 1990 and 2000. In the simulations the trajectory of $\mathrm{A}_{\mathrm{j}, \mathrm{t}}$ to match the evolution of GDP $\left(\mathrm{Y}_{\mathrm{j}, \mathrm{t}}\right)$ in each country given the observed size and structure of the labour force was calibrated the assumption that dyadic residual factors are constant $\left(\mathrm{V}_{\mathrm{i} j, \mathrm{~s}, \mathrm{t}}=\mathrm{V}_{\mathrm{i}, \mathrm{s}, 2010}\right)$. The latter assumption implies that possible changes in migration costs and migration policies are ignored.

Results are depicted on Figure 1. Figure 1.a compares the evolution of actual and predicted worldwide migration stocks by decade. The aggregate data give a stock of 55 million migrants aged 25 to 64 in 1970, and of 120 million migrants in 2010. The model almost exactly matches this evolution whatever the technological scenario. ${ }^{5}$ Three technological variants are considered: the first

\footnotetext{
${ }^{5}$ Given the calibration strategy the model perfectly matches the 2010 data.
} 
assumes ES = 2 and the maximalist scenario for the skill-biased technological externality, the second assumes ES $=2$ and the minimalist level of externality, the third assumes ES $=3$ and the maximalist level of skill-biased externality. These three variants cannot be visually distinguished on Figure 1.a as the simulated trajectories almost perfectly coincide. Although technological variants drastically affect within-country income disparities, (in particular, the wage rate of college graduates), they have negligible effects on aggregate migration stocks. This is due to the fact that income disparities are mostly governed by between-country inequality (i.e. by the TFP levels, which are calibrated under each scenario to match the observed levels of income per capita) and that the worldwide proportion of college graduates is so small that changes in their migration propensity have negligible aggregate effects.

Figures 1.b to 1.d illustrate the capacity of the model to match the decadal distributions of immigrant stocks by destination and the decadal distributions of emigrant stocks by origin. To depict the accuracy of fit the observed and simulated stocks of immigrants and emigrants for each country and for each decade are compared. By construction the predicted migrant stocks are perfectly matched in the year 2010. For previous years the correlation is unsurprisingly smaller; it decreases with the distance from the year 2010. This is because the model does neither identify past variations in migration policies nor past changes in net amenities and non-pecuniary push/pull factors (conflicts, political unrest, etc.). ${ }^{6}$ Nevertheless Figure 1.b shows that the fit is excellent in 2000 (correlation of 0.98 with observations) and Figures 1.c and 1.d do not show evidence of many major outliers for the year 1970 (the correlation equals 0.76 for immigrant stocks and equals 0.69 for emigrant stocks).

\section{Root drivers of past migration}

Although the model is simple and ignores some features of the real world (inertia in migration stocks, network effects, endogeneity of native population changes, capital accumulation, etc.), its backcasts fit the historical trends in the worldwide aggregate stock of migrants in immigration stocks to all destination countries and in emigration stocks from all origin countries very well. This demonstrates the capacity of such an abstract macroeconomic model to identify the main sources of variation and to predict long-run migration trends.

${ }^{6}$ E.g. Schengen agreement in the EU, changes in the H1B visa policy in the US, points-system schemes in Canada, Australia, New Zealand, guest worker programmes in the Persian Gulf, etc. Important gaps between the observed and predicted migration stocks recorded in the data also come from the non-consideration of the independence of Pakistan from India, the collapse of the Soviet Union, the end of the French-Algerian and the Vietnam wars, the conflict between Cuba and the US, the flows of Russian Jews to Israel in the late 1980s (the so-called Post-Soviet aliyah). 


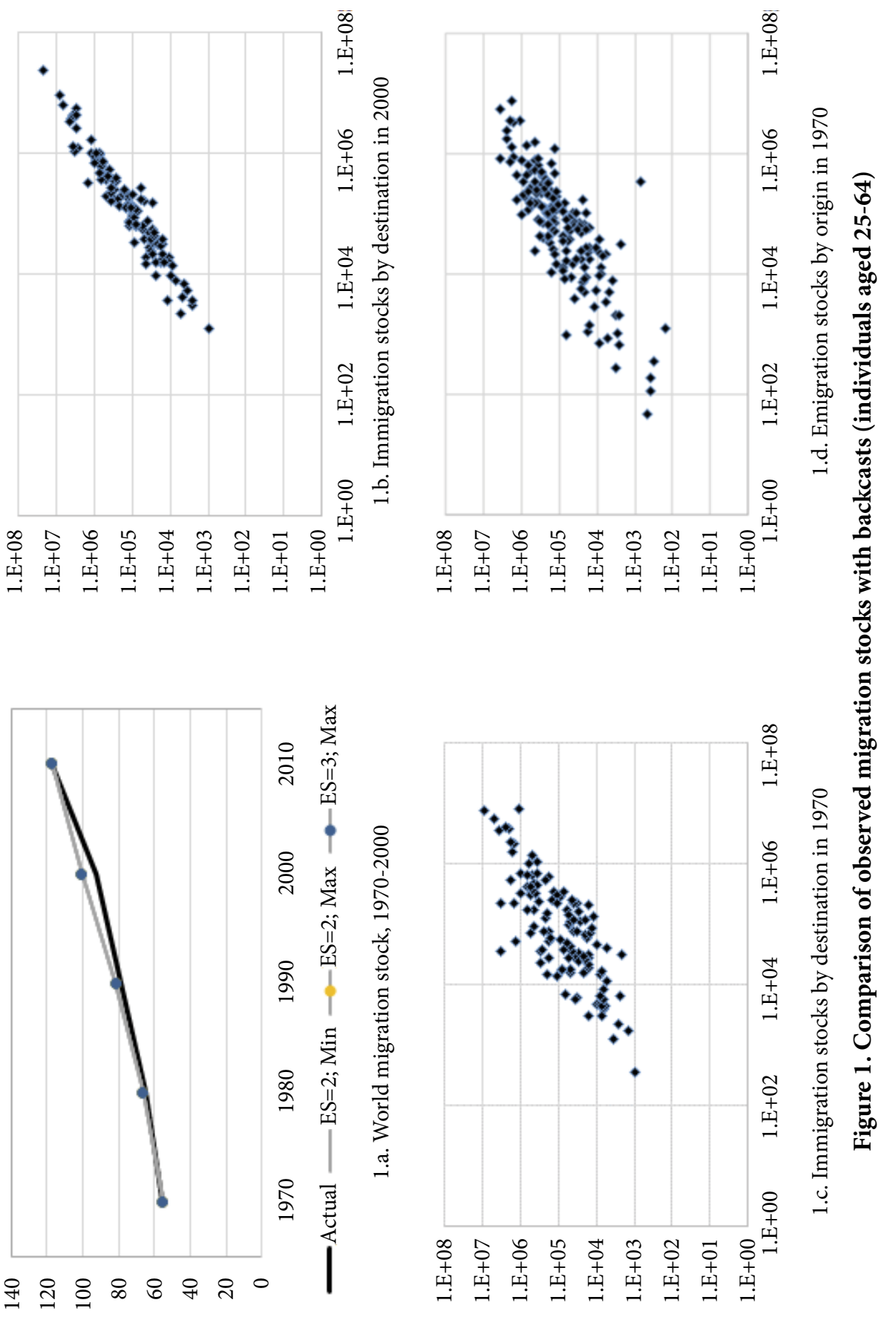




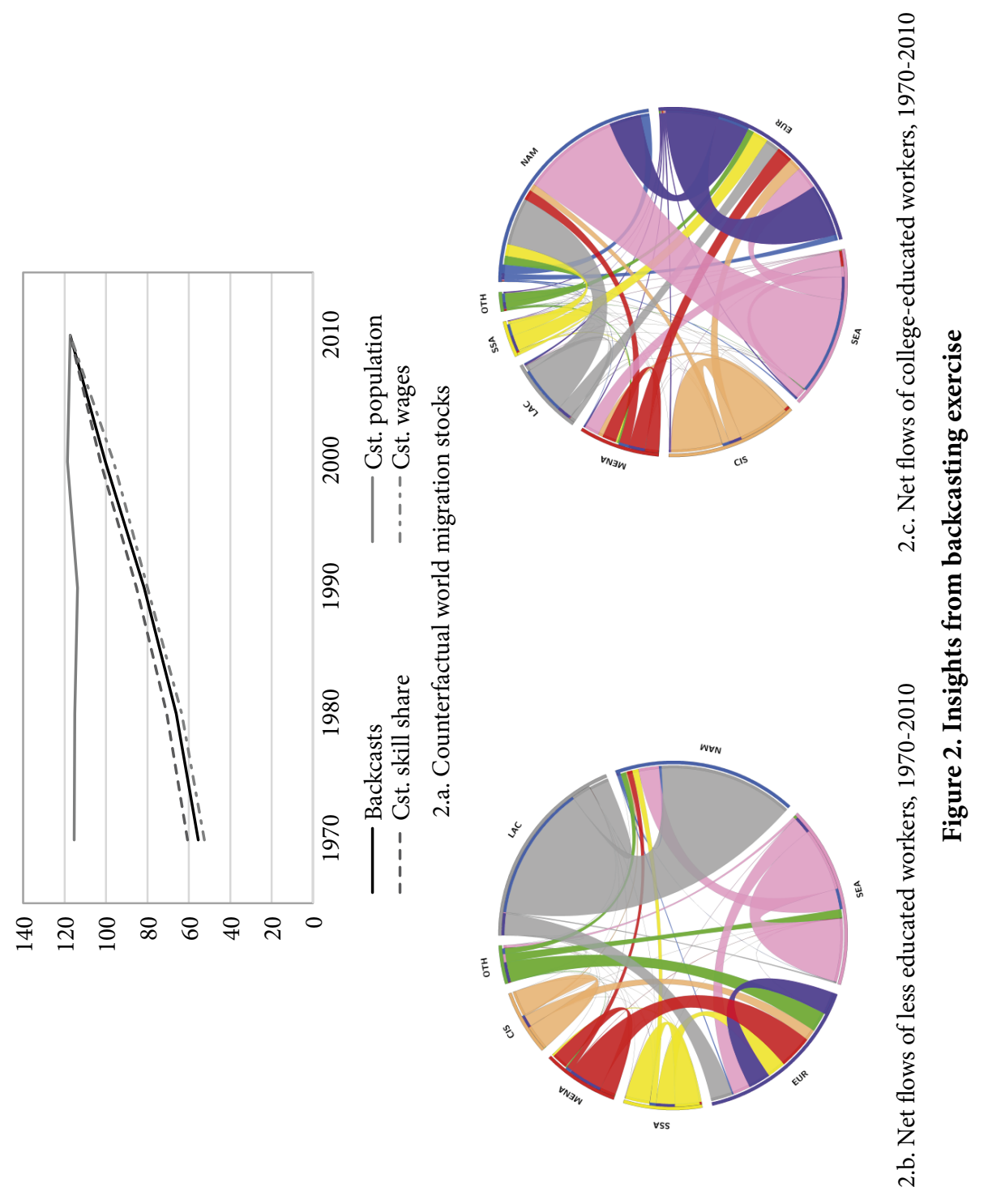


Hence, to identify the root drivers of migration, counterfactual historical trends (with constant distributions of income, education level or native population size) were simulated and compared with the backcasts of Figure 1. The first counterfactual neutralizes demographic changes that occurred between 1970 and 2010; it assumes that the size of the working-age native population is kept constant at the 2010 level in all countries. The second counterfactual neutralizes the changes in education; it assumes that the share of college graduates is kept constant in all countries. The third counterfactual neutralizes the changes in income disparities; it assumes constant wage rates in all countries.

Results are presented on Figure 2.a. They reveal that past changes/rises in education marginally increased the worldwide migration stock while the past changes/decreases in income inequality marginally reduced it. However these effects are quantitatively small. This is because the rise in human capital has been limited in poor countries and income disparities have been stable for the last fifty years (with the exception of emerging countries). On the contrary, demographic changes explain a large amount of the variability in migration stocks. If the population of each country had been constant the stock of worldwide migrants in 1970 would have only been $2 \%$ smaller than the current stocks. This confirms that past changes in aggregate migrant stocks were predominantly governed by demographic imbalances: in particular the ratio of native population between developing and high-income countries increased from 3.5 in 1970 to 5.5 in 2010.

The model also sheds light on the skill structure of past migration flows. As historical migration data by skill group do not exist the model was utilized to "backcast" the global net flows of college-educated and less educated workers between regions. The scenario with ES $=2$ and with maximalist skill-biased externalities was used (It should be remembered that the results are virtually insensitive to the technological scenario). For each pair of countries the net flow as the difference between the stock of migrants in 2010 and that of 1970 was computed. On Figures 2.b and 2.c, countries are grouped in eight regions and circular ideograms to highlight the major components of the matrix of net flows were used. Europe (in dark blue), Western offshoots (NAM in light blue), Middle East and Northern Africa (MENA in red), sub-Saharan Africa (SSA in yellow), South and East Asia including South and South-East Asia (SEA in pink), the former Soviet countries (CIS in orange), Latin America and the Caribbean (LAC in grey), and other countries (OTH in green) are distinguished. Origin and destination regions are represented as segments on the outline of the circle. Net flows are coloured according to their origin and their width is proportional to their size. The direction of the flow is captured by the colours of the outside (i.e. country of origin) and inside (i.e. country of destination) borders of the circle.

Figure 2.b focuses on the net flows of less educated workers. The worldwide net flow of low-skilled migrants equals 35.2 million over the 1970-2010 period. 
The ten main regional corridors account for $79 \%$ of the total and industrialized regions appear six times as a main destination. By decreasing order of magnitude they include Latin America to North America (27.6\%), migration within the South and East Asian region (13\%), MENA to Europe (6.8\%), migration between former Soviet countries (5.2\%), migration within sub-Saharan Africa (5.1\%), intra-European movements (4.5\%), Latin America to Europe (4.4\%), South and East Asia to Western offshoots (4.2\%), others to Europe (4.0\%), and migration between Latin American countries (4.0\%). It is worth noting that the low-skilled mobility from sub-Saharan Africa to Europe is not part of the top ten: it only represents $3.8 \%$ of the total (11th largest regional corridor).

Figure 2.c represents the net flows of college graduates. The worldwide net flow of high-skilled migrants equals 27.6 million over the 1970-2010 period. The ten main regional corridors account for $74 \%$ of the total. A major difference with the low-skilled is that industrialized regions appear 9 times as a main destination, at least if the Persian Gulf countries (as part of the MENA region) are treated as industrialized countries. By decreasing order of magnitude the top-10 includes South and East Asia to Western offshoots (19.8\% of the total), intra-European movements (10.7\%), migration between former Soviet countries (10.5\%), Latin America to Western offshoots (9.7\%), Europe to Western offshoots (6.5\%), South and East Asia to Europe (4.6\%), MENA to Europe (3.3\%), sub-Saharan Africa to Europe (3.2\%), South and East Asia to the MENA (3.1\%), and Latin America to Europe (2.9\%).

\section{Forecasts for the 21st century}

A parameterized model to produce projections of migration stocks and income disparities for the 21 st century under two socio-demographic scenarios is now used. Aggregate projection results are depicted on Figure 3. The sociodemographic scenarios are drawn from Lutz, Butz, \& Samir (2014) who produce population projections by age, sex and education levels for all countries of the world. Scenario SSP2 assumes low population growth and rapid progress in education; scenario SSP3 assumes high population growth and slow progress in education. These differences are illustrated on Figures 3.a and 3.b.

Figure 3.c and 3.d show the resulting trajectory of predicted emigration and immigration rates. In line with the backcasting exercise three technological variants are considered: the first assumes $\mathrm{ES}=2$ and the maximalist scenario for aggregate and skill-biased technological externalities, the second assumes $\mathrm{ES}=2$ and the minimalist levels for both externalities, the third assumes $\mathrm{ES}=3$ and the maximalist externality levels.

Figure 3.c depicts the evolution of emigration rates defined as the ratio of emigrants to natives originating from developing countries. The average emigration rate equals $3.1 \%$ in 2010 . Under SSP2 it is predicted to be twice as 

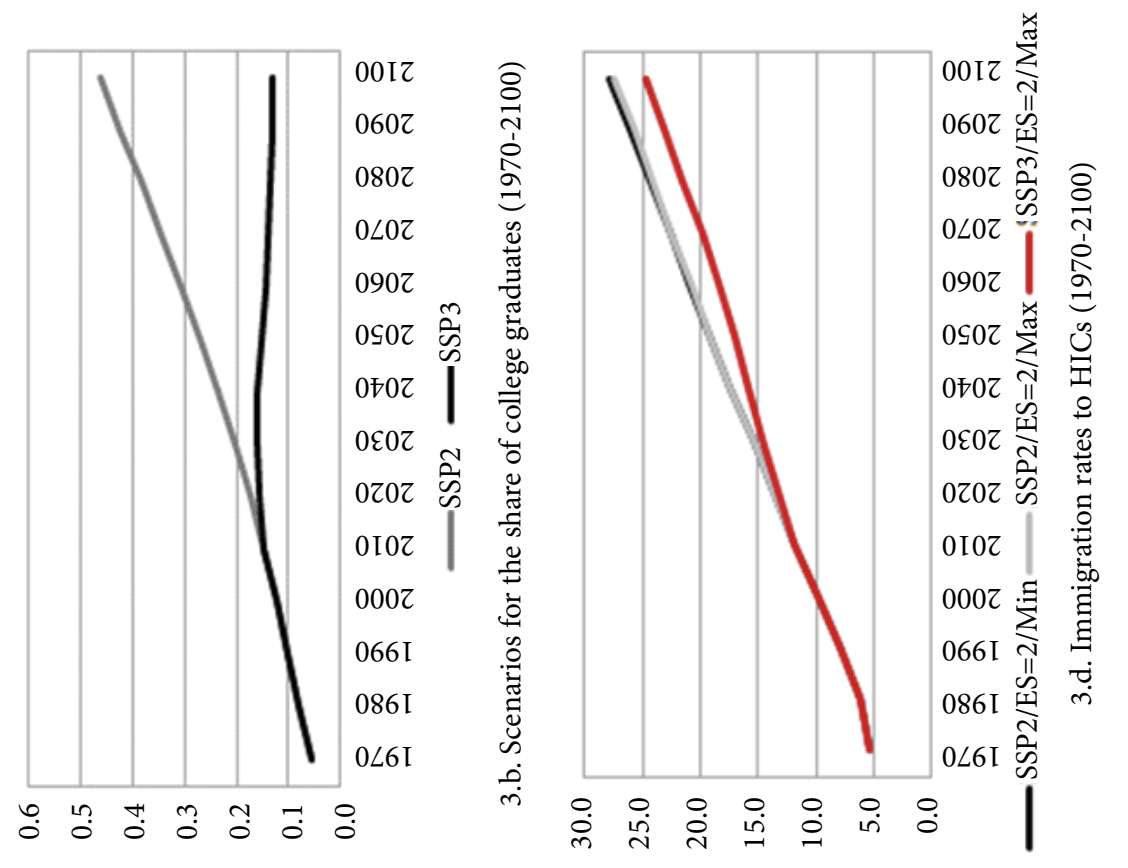

0̊.

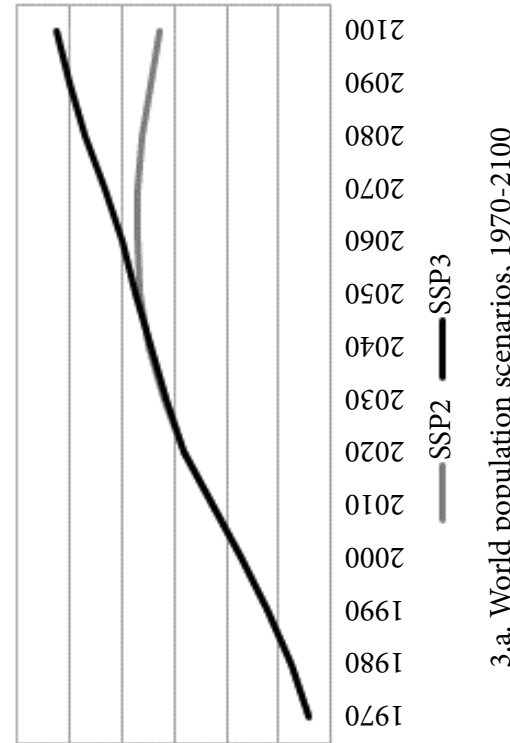

앙 이

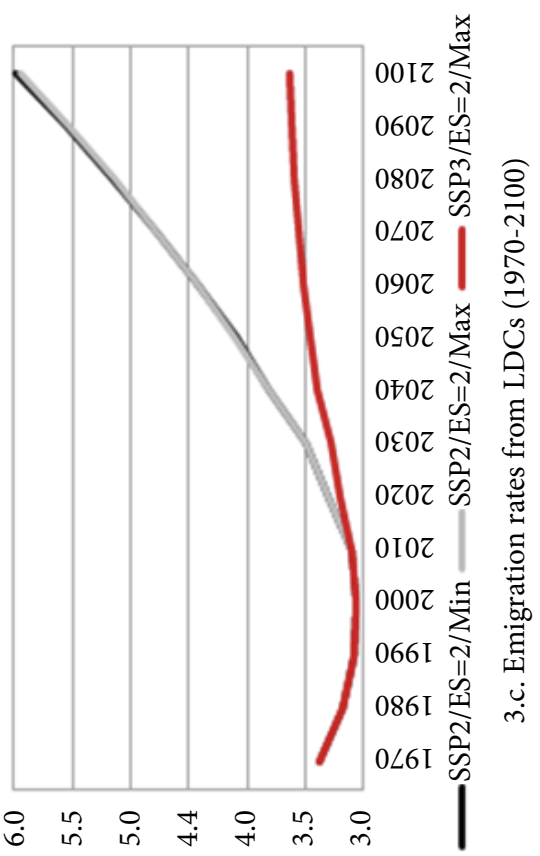


large in the year 2100; under SSP3 it reaches only 3.6\%. These emigration rates are governed by the change in the average level of education in the developing world. Under SSP2 progress in education makes people more mobile (remember college graduates migrate more than the less educated). Under SSP3 emigration rates remain fairly stable over time given the slower progress in education. Figure 3.d depicts the evolution of the average immigration rate of OECD member states, defined as the proportion of foreign-born in the total population. This proportion equals $12 \%$ in the year 2010 and it is expected to drastically increase over the 21 st century. Nevertheless a remarkable result is that the magnitude of the change is highly insensitive to socio-demographic and technological scenarios. Under SSP3 emigration rates from developing

Table 1. Proportion of working-age immigrants by main destination

\begin{tabular}{|c|c|c|c|c|c|c|c|c|}
\hline Year & 2010 & 2020 & 2030 & 2040 & 2050 & 2060 & 2100 & $\Delta$ \\
\hline & \multicolumn{8}{|c|}{ SPP2, ES = 2, Maximalist } \\
\hline EU15 & 14.5 & 16.8 & 19.3 & 22.2 & 24.7 & 26.8 & 36.5 & 21.2 \\
\hline France & 14.7 & 18.0 & 21.0 & 24.0 & 26.2 & 28.2 & 36.5 & 21.8 \\
\hline Germany & 15.9 & 17.3 & 19.3 & 21.3 & 22.0 & 22.8 & 24.9 & 9.0 \\
\hline Italy & 10.5 & 11.8 & 13.1 & 14.8 & 15.9 & 16.3 & 18.7 & 8.2 \\
\hline Poland & 0.5 & 0.6 & 0.6 & 0.7 & 0.8 & 0.8 & 1.0 & 0.5 \\
\hline Spain & 14.9 & 16.8 & 19.2 & 22.0 & 25.2 & 26.6 & 29.9 & 15.0 \\
\hline United Kingdom & 16.5 & 19.9 & 24.2 & 28.8 & 32.8 & 37.2 & 52.3 & 35.9 \\
\hline United States & 17.7 & 20.4 & 23.3 & 25.2 & 26.7 & 28.0 & 31.9 & 14.3 \\
\hline Canada & 24.5 & 29.4 & 35.3 & 40.1 & 44.3 & 48.4 & 60.0 & 35.6 \\
\hline \multirow[t]{2}{*}{ OECD } & 11.9 & 13.7 & 15.5 & 17.4 & 19.2 & 20.8 & 27.5 & 15.6 \\
\hline & \multicolumn{8}{|c|}{ SPP3, ES = 2, Maximalist } \\
\hline EU15 & 14.5 & 16.4 & 18.4 & 20.7 & 22.8 & 25.3 & 38.9 & 24.3 \\
\hline France & 14.7 & 17.4 & 19.4 & 21.2 & 22.7 & 24.6 & 36.3 & 22.2 \\
\hline Germany & 15.9 & 17.3 & 19.3 & 21.5 & 23.2 & 25.6 & 40.0 & 24.1 \\
\hline Italy & 10.5 & 11.8 & 13.2 & 15.2 & 17.3 & 19.3 & 32.1 & 21.6 \\
\hline Poland & 0.5 & 0.6 & 0.6 & 0.6 & 0.7 & 0.8 & 1.3 & 0.8 \\
\hline Spain & 14.9 & 16.6 & 18.7 & 21.4 & 25.2 & 28.1 & 41.9 & 27.0 \\
\hline United Kingdom & 16.5 & 18.6 & 21.3 & 23.4 & 25.5 & 28.6 & 43.6 & 26.2 \\
\hline United States & 17.7 & 19.8 & 22.2 & 23.5 & 25.3 & 27.6 & 40.1 & 22.4 \\
\hline Canada & 24.5 & 27.4 & 31.2 & 33.5 & 35.7 & 39.1 & 54.2 & 29.8 \\
\hline OECD & 11.9 & 13.3 & 14.6 & 15.7 & 16.9 & 18.3 & 24.6 & 12.7 \\
\hline
\end{tabular}


countries vary little but population growth is large. Under the SSP2 scenario the rise in emigration rates is larger but it is partly offset by the fall in the population growth rates of developing countries. By the year 2100 the share of immigrants reaches $27.8 \%$ under SSP2 and $24.6 \%$ under SSP3.

Table 1 provides projections of immigration rates for the main OECD countries and for constant immigration policies. Results obtained under the SSP2 socio-demographic scenario are presented in the top panel; results obtained under SSP3 are presented in the bottom panel. The last column gives the variation in the immigration rate between 2010 and 2100 (denoted by $\Delta$ ). In both scenarios the variant with ES $=2$ and full technological externalities is considered being the technological scenario that is the most compatible with future educational changes. Under SSP2 and over the 21st century the proportion of immigrants increases by $21.2 \%$ in the EU15 and by $14.3 \%$ in the United States. The greatest variations are obtained for the United Kingdom $(+35.9 \%)$ and for Canada (+35.6\%). As for Poland the model is parameterized on the year 2010, a year in which the immigration rate was small (0.5\%). Still the Polish immigration rate increases twofold during the 21 st century (from $0.5 \%$ in 2010 to $1.0 \%$ in 2100). Under SSP3 the average population growth rates are larger in developing countries, with the exception of Asia. The proportion of immigrants increases by $24.3 \%$ in the EU15 and by $22.4 \%$ in the United States. The greatest variations are obtained for Spain (+27\%), the United Kingdom $(+26.2 \%)$ and Canada $(+29.8 \%)$. In Poland the immigration rate increases from $0.5 \%$ in 2010 to $1.3 \%$ in 2100 . Projections for the coming 50 years are rather insensitive to the socio-demographic scenario. In line with Hanson \& McIntosh (2016), or with Docquier \& Machado (2007), future migration pressures mainly affect European countries and are mostly due to rising migration flows from developing countries.

\section{Conclusion}

The recent refugee crisis has placed migration policy in the forefront of the global policy debate. While the chief cause of the current crisis is the conflict and political unrest in the Middle East and Africa, the recent trends and forecast evolution of the world economy strongly suggest that there may be further episodes of large-scale migration in the near future in Europe and other OECD countries. Specifically the underlying root causes of increased migration (demographic imbalances, economic inequality, increased globalization, political instability, climatic changes) are all projected to exert a stronger in influence in the coming decades. Relying on socio-demographic and technological scenarios this paper produces integrated hindcasts and forecasts of income and bilateral migration stocks for all pairs of countries. The model fits the trends in international migration of the last 40 years very well, and demonstrates that 
historical trends were mostly governed by demographic changes. Turning to the migration prospects for the 21st century it was also found that world migration prospects are mainly governed by socio-demographic changes; they are virtually insensitive to the technological environment. A highly robust increase in immigration pressures in general and in European immigration in particular is predicted. These migration pressures are mostly explained by the demographic changes in sub-Saharan Africa and in the MENA countries. More than ever the management of immigration should represent a major societal challenge for European countries in the 21st century.

\section{References}

Angrist, J. (1995). The economic returns to schooling in the West Bank and Gaza Strip. American Economic Review, 85(5), 1065-1087.

Arslan, C., Dumont, J.-C., Kone, Z., Moullan, Y., Ozden, C., Parsons, C.R., Xenogiani, T. (2015). A new prole of migrants in the aftermath of the recent economic crisis. OECD Social, Employment and Migration Working Papers, 160, OECD Publishing.

Bertoli, S., Fernandez-Huertas Moraga, J. (2013). Multilateral resistance to migration. Journal of Development Economics, 102(C), 79-100.

Dao, T.H., Docquier, F., Maurel, M., Schaus, P. (2017). Global migration in the 20th and 21st centuries: the unstoppable force of demography. Manuscript.

Docquier, F., Machado, J. (2017). Income disparities, population and migration flows over the 21st century. Italian Journal of Economics, 3(2), 125-149.

Hanson, G., McIntosh, C. (2016). Is the Mediterranean the new Rio Grande? US and EU immigration pressures in the long run. Journal of Economic Perspectives, 30(4), 57-82.

Lutz, W., Butz, W.P., Samir, K.C. (2014). World population and human capital in the twenty-first century. Oxford: Oxford University Press.

Ottaviano, G.I.P., Peri, G. (2012). Rethinking the effect of immigration on wages. Journal of the European Economic Association, 10, 152-197.

Ozden, C., Parsons, C.R., Schiff, M., Walmsley, T.L. (2011). Where on earth is everybody? The evolution of global bilateral migration 1960-2000. World Bank Economic Review, 25(1), 12-56. 